\title{
P268S in NOD2 associates with susceptibility to Parkinson's disease in Chinese population
}

\author{
Qilin $\mathrm{Ma}^{1 \dagger}$, Xingkai $\mathrm{An}^{1 \dagger}$, Zhiming $\mathrm{Li}^{2 \dagger}$, Huanjing Zhang ${ }^{2}$, Wenqing Huang ${ }^{2}$, Liangliang $\mathrm{Cai}^{2}$, Peng $\mathrm{Hu}^{2}$, \\ Qing Lin ${ }^{1,2^{*}}$ and Chi-Meng Tzeng ${ }^{2^{*}}$
}

\begin{abstract}
Background: The cause of almost all cases of Parkinson's disease (PD) remains unknown. Recent years have seen an explosion in the rate of discovery of genetic defects linked to PD. Different racial and geographical populations may have different distributions of genetic variants.

Methods: In the current study, we screened the following genetic variants, including some rare mutations and single nucleotide polymorphisms (SNPs), in a pedigree and cases-controls. To best of our knowledge, we first screened these variants known to be associated with neurodegeneration disease, E46K (rs104893875) in SNCA, A1442P in LRRK2, IVS9 in PARK2, A350V in SLC41A1, P268S (rs2066842), R702W (rs2066844), G908R (rs2066845), 1007fs (rs2066847) in NOD2 and G2385R (rs34778348) in LRRK2 from southern China population. Genotyping was performed by jointly using primers overlapping polymerase chain reaction (PCR) site-directed mutagenesis, restriction fragment length polymorphism (RFLP), and capillary electrophoresis (CE).
\end{abstract}

Results: We didn't discover above 9 variants in the family members of the pedigree. Furthermore, of 237 patients with sporadic Parkinson's disease and 190 controls, no heterozygosity or homozygosity were found from E46K, A1442P, A350V, R702W, G908R, or 1007fs but heterozygosity onto G2385R, IVS9, and P268S. No significant difference between cases and controls was found in both allele frequency $(P=0.572)$ and genotype frequency $(P=0.348)$ of IVS9. However, significant differences in genotype frequency $(P=0.009)$ of $G 2385 R$ were consistent with prior observation. Eight patients with Parkinson's disease (2 women and 6 men are over the age of 50 years at onset of PD) carried the P268S heterozygous variation in NOD2. There was no heterozygosity or homozygosity of P268S in the controls. Genotype frequency of P268S ( $P=0.0450)$ had significant differences.

Conclusions: Our results suggested that the P268S variant in NOD2 might be a risk factor for susceptibility to sporadic Parkinson's disease in Chinese populations. It also implied that the inflammatory response may play a role in PD.

Keywords: Parkinson's disease, Variants, P268S

\section{Background}

Parkinson's disease (PD) is a complex neurodegenerative disease caused by a variety of factors. The incidence in the population over the age of 65 is about $1.8 \%$ [1]. The major clinical features of PD include resting tremor, bradykinesia and rigidity [2]. The pathological features of PD include progressive loss of dopaminergic neurons from the substantia

\footnotetext{
* Correspondence: linging2005602@aliyun.com; cmtzeng@xmu.edu.cn ${ }^{\dagger}$ Equal contributors

'Department of Neurology, The First Affiliated Hospital of Xiamen University, Xiamen, Fujian 361003, China

${ }^{2}$ School of Pharmaceutical Sciences, Xiamen University, Xiamen, Fujian 361005, China
}

nigra pars compacta and the presence of intercellular Lewy bodies in surviving neurons [3]. The cause of PD is unclear, but it is generally considered to be associated with the impairment in degradation of ubiquitin proteasome system (UPS), mitochondrial dysfunction, and oxidative stress [4-6]. We hypothesize that genetic and environmental factors and aging together lead to the development of PD. In this study, we investigated five genes, including $S N C A, L R R K 2$, PARK2, SLC41A1, and NOD2, all of which might be involved in the cytological mechanisms of neurodegeneration disease aiming to identify genetic variants associated with sporadic PD in Chinese patients and understand the genetic etiology of PD.

\section{Biomed Central}

(c) 2013 Ma et al.; licensee BioMed Central Ltd. This is an Open Access article distributed under the terms of the Creative Commons Attribution License (http://creativecommons.org/licenses/by/2.0), which permits unrestricted use, distribution, and reproduction in any medium, provided the original work is properly cited. 
The first gene to be identified as associated with PD was SNCA (PARK1/4), which encodes $\alpha$-synuclein. The major mutations in SNCA include A53T, A30P, and E46K [7-9]. Although these mutations account for less than $1 \%$ of the cases, patients carrying these mutations have obviously clinical phenotypes [8]. The A53T and A30P mutations have been found in Chinese patients with sporadic PD [10]. However, the association of E46K with sporadic PD has not been reported in Chinese patients.

LRRK2 (PARK8) encodes a large protein containing five functional domains, involved in a number of physiological functions, including substrate binding, protein phosphorylation and protein interactions [11]. The most common mutation G2019 of LRRK2 in European populations presents less than $0.1 \%$ in Asian individuals [12]. The G2385R was at a significantly higher frequency in Asian patients than in controls [13]. One of the purposes of this study is to revalidate this variant in southern China. In addition, Yue Huang found A1442P in pedigrees of the Australian patients and considered it pathogenic, because it is conserved across many species and a substitution of Ala with Pro can change the secondary structure of proteins [14]. However, A1442P has not been further confirmed from a large number of cases and other populations.

The most common cause of young-onset sporadic PD is autosomal recessive PARK2 mutation [15]. The E3 ubiquitin ligase, parkin, which is encoded by $P A R K 2$, can specifically degrade UPS through tagging ubiquitin on protein [16]. Exon deletion, insertion, and point mutations in PARK2 have been found in different ethnic groups [17]. In 2009, Yih-Ru Wu screened 506 Taiwan sporadic patients with age of onset below 50 years for PARK2 gene mutation and identified a novel IVS9 insertion $\left(c .1084\right.$ intron $^{+}$) [18]. The c.1084intron ${ }^{+}$was due to a $\mathrm{G}>\mathrm{A}$ polymorphism at position -6 of a cryptic splice acceptor site within IVS9.

In recent years, genome-wide association studies (GWAS) have identified a number of new susceptibility loci associated with PD in different ethnic groups. Of these loci, the most striking locus is PARK16, which is located in 1q23 and contains 5 genes (SLC45A3, NUCKS1, RAB7L1, SLC41A1, and PM20D1) [19]. SLC41A1 encodes a $56 \mathrm{kDa} \mathrm{Mg}^{2+}$ transporter consisting of 513 amino acids, it has been proposed that PD might be associated with lack of $\mathrm{Ca}^{2+}$ and $\mathrm{Mg}^{2+}$ in the brain [20]. In 2010, Arianna Tucci sequenced PARK16 in 182 patients with $\mathrm{PD}$ in the United Kingdom and found A350V in SLC41A1, but failed to detect it in a large series of ethnicity-matched controls $(n=483)$ [19]. To inspect whether this coding mutations may or may not be the disease-causing mutation, we aim to screen A350V in Chinese Han populations.
Several obtained findings suggest that inflammation also contributes to the pathogenesis of PD [21-23]. It has been reported that the $\mathrm{G} 174 \mathrm{C}$ variant in the $I L-6$ promoter may influence the risk for developing PD, particularly regarding early age of onset PD [24]. Recent studies revealed that NF-kB-mediated inflammation might also play an important role in the pathogenesis of PD [25,26]. NOD (nucleotide-binding oligomerization domain) proteins, i.e. NOD1 (a product of CARD4 gene) and NOD2 (encoded by NOD2), are intracellular signaling molecules that recognize bacterial components, mediate the activation of NF- $\mathrm{kB}$ and induce or enhance apoptosis [27]. In 2007, Monika Bialecka et al. screened 308 Portland patients for 3 variants (R702W, G908R, and 1007fs) in NOD2 which were associated with Crohn's disease (CD) in Europeans. They found that NOD2 might be associated with susceptibility to PD [28]. Although inflammatory response has long been considered as one of the factors for PD development, it has not yet been reported that R702W, G908R, 1007fs and P268S in NOD2 is associated with Chinese PD patients.

In this study, we screened 237 patients with sporadic PD and 190 controls for the 9 variants, E46K (rs104893875), G2385R (rs34778348), A1442P, IVS9, A350V, R702W (rs2066844), G908R (rs2066845), 1007fs (rs2066847) and P268S (rs2066842), in 5 genes which are possibly found to be associated with Chinese PD patients, including SNCA, LRRK2, PARK2, SLC41A1, and NOD2. These variants included both rare mutations (e.g. E46K and A1442P) and SNPs, so we also screened them in a pedigree with two PD cases. In this way, we aimed to provide references for the study of disease-causing or susceptibility gene for PD. In addition, using the overlap extension polymerase chain reaction (PCR)-based site-directed mutagenesis, we constructed wild-type and homozygous mutant plasmids for these variants, which were used as controls to determine variants in this study.

\section{Material and methods \\ Study subjects}

A total of 237 sporadic patients with PD (94 women and 143 men) and a pedigree with two PD cases were recruited from Xiamen First Hospital, Fujian Province, China. The average age of enrollment was $60.3 \pm 11.3$, ranging from 25 to 83 years. Their average age of onset was $56.4 \pm 10.8$ years, ranging from 23 to 80 years. Of these patients, 51 (21.5\%) had early-onset PD (EOPD), defined as the age at onset $<50$ years; 186 (78.5\%) cases had late-onset PD (LOPD), with age of onset $\geq 50$ years. Patients were independently diagnosed by two neurologists. Diagnostic criteria were taken from the United Kingdom PD Brain Bank [29]. The severity of the disease was determined using the Unified Parkinson's Disease Rating Scale (UPDRS). The control group consisted of 
190 individuals (75 women and 115 men), with an average age of $51.7 \pm 9.8$ years (ranging from 23 to 80 years). The cases and controls were matched with respect to age, gender, and place of residence. This study was approved by the Xiamen First Hospital Ethics Committee. Informed consent was obtained from all participants.

\section{Genomic DNA extraction}

Five milliliters of peripheral blood with ethylene diamine tetraacetic acid (EDTA) anticoagulant was collected from each participant. Genomic DNA was extracted using the MagCore Genomic DNA Whole Blood Kit and HF-16 extractor (Cat. No. MGB400-04, RBC Bioscience Taiwan) according to the manufacturer's instructions and stored all samples at $-20^{\circ} \mathrm{C}$ before use.

\section{PCR amplification}

Primers (Table 1) were designed using the software Primer Premier 5 according to the change of restriction sites, caused by the mutation. Primers were synthesized by Sangon Biotech (Shanghai, China).

\section{Restriction endonuclease analysis}

Target variants were detected using the PCR-RFLP (restriction fragment length polymorphism) method.
The digestion reaction and restriction enzyme digestion conditions were taken from the manuals included with the restriction enzymes purchased from the New England BioLab (United States). Then $20 \mu$ of digestion products were loaded on $2 \%$ agarose gel containing ethidium bromide, electrophoresed under $100 \mathrm{~V}$ for $30 \mathrm{~min}$ in $1 \times \mathrm{TAE}$, and imaged using the gel imager. Digestion results of homozygous mutants, heterozygous mutants, and wildtype are shown in Table 1.

\section{DNA sequencing}

Based on the results from PCR-RFLP and site-directed mutagenesis, the target fragments were re-amplified using PCR. PCR products were purified using a DNA gel purification kit, sequenced using the dideoxy four-color fluorescence method on an automatic sequencer (ABI, U.S.), and compared using GenBank data to confirm the mutation sites.

\section{Capillary electrophoresis (CE)}

In this study, we initially established the test method using $\mathrm{CE}$ to detect gene polymorphisms for PD. Briefly, based on the susceptibility gene polymorphisms of PD identified from PCR-RFLP, restriction fragments were detected using capillary electrophoresis (BIOptics

Table 1 Primer sequences, PCR conditions and restriction digestion predictions

\begin{tabular}{|c|c|c|c|c|c|}
\hline Polymorphism & Primer sequences $\left(5^{\prime} \rightarrow 3^{\prime}\right)$ & $\begin{array}{l}\text { Annealing } \\
\text { temperature }\left({ }^{\circ} \mathrm{C}\right)\end{array}$ & $\begin{array}{l}\text { Restriction } \\
\text { enzyme }\end{array}$ & $\begin{array}{l}\text { Amplified products } \\
\text { length (bp) }\end{array}$ & $\begin{array}{l}\text { Restriction products } \\
\text { length (bp) }\end{array}$ \\
\hline \multirow[t]{2}{*}{ E46K } & F: TGATGTGGGAACAAAGGGGA & 58 & Bsall & 747 & 46E allele: 287,460 \\
\hline & R: GTGTTCCTGAAATGCACTCTGA & & & & 46K allele: 747 \\
\hline \multirow[t]{2}{*}{ A1442P } & F: GAGACTAAACTGCTGCTTGC & 58 & Hhal & 801 & 1442A allele: 671,130 \\
\hline & R: GTAATCTCGTATGGCAGGGA & & & & 1442P allele: 801 \\
\hline \multirow[t]{2}{*}{ A350V } & F: TCAGTGGTCTITGCGTCATT & 58 & Mwol & 302 & 350A allele: 94,208 \\
\hline & R: CTGTCCTITTACTCTGCTCCC & & & & 350V allele: 302 \\
\hline \multirow[t]{2}{*}{ P268S } & F: AGCCCATTGTCTGGTTAGGT & 58 & $\mathrm{BamHI}$ & 309 & 268P allele: 309 \\
\hline & R: ACAGTGTCCGCATCGTCAT & & & & 2685 allele: 225,84 \\
\hline \multirow[t]{2}{*}{ R702W } & F: AGATCACAGCAGCCTTCC & 63 & Mspl & 185 & 702R allele: $20,35,54,76$ \\
\hline & R: CACGCTCTTGGCCTCACC & & & & 702W allele: 20, 35, 130 \\
\hline \multirow[t]{2}{*}{ G908R } & F: CCCAGCTCCTCCCTCTTC & 63 & Hin6l & 380 & 908G allele: 380 \\
\hline & R: AAGTCTGTAATGTAAAGCCAC & & & & 908R allele: 242, 138 \\
\hline \multirow[t]{2}{*}{$1007 \mathrm{fs}$} & $\begin{array}{l}\text { F: } \\
\text { GGCAGAAGCCCTCCTGCAGGGCC }\end{array}$ & 58 & Apal & 151 & Wild type allele: 151 \\
\hline & R: CCTCAAAATTCTGCCATTCC & & & & $1007 f$ allele: 130, 21 \\
\hline \multirow[t]{2}{*}{ IVS9* } & $\begin{array}{l}\text { F: } \\
\text { ACTCCTGCGCTTGATTAAGGCAAT }\end{array}$ & 58 & Xhol & 775 & Wild type allele: 318,457 \\
\hline & $\begin{array}{l}\text { R: } \\
\text { TTGGAATTAGCTGTTCCTTCGGG }\end{array}$ & & & & IVS9 G $\rightarrow$ A allele: 775 \\
\hline \multirow[t]{2}{*}{ G2385R } & $\begin{array}{l}\text { F: } \\
\text { AGACACTGCTCTCTATATTGCTAAG }\end{array}$ & 58 & AcCl & 261 & 2385G:261 \\
\hline & R: CTGAAAAGATGGTGCTGAGAAG & & & & 2385R:77,184 \\
\hline
\end{tabular}

*: IVS9: Intervening sequence 9, PARK2. 
Qsep100 dna-CE, Taiwan), which used a molten molding silica capillary column with an inner diameter of $75 \mu \mathrm{l}$ and column length of $150 \mathrm{~mm}$ and Mops-Tris buffer of $\mathrm{pH}$ 7.55. Then $0.5 \mu \mathrm{l}$ of sample was electrically injected in $4 \mathrm{kV} \times 15 \mathrm{~s}$ at $25^{\circ} \mathrm{C}$, electrophoresed at a constant voltage of $8 \mathrm{Kv}$, and detected for the laser-induced ethidium bromide emission wavelength at $590 \mathrm{~nm}$. The gel electrophoresis profiles were compared to determine the genotypes.

\section{Statistical analysis}

SPSS 18.0 (Statistical Package for the Social Sciences, version 18.0 for Windows) was used for statistical analysis. Allele and genotype frequencies were compared between cases and controls using the Fisher's exact test. To avoid multiple easily false, false discovery rate was used to correct $\mathrm{p}$ values. Odds ratios and 95\% confidence intervals were calculated. A two-sided $P$ value $\leq 0.05$ was considered statistically significant. Power was calculated by Power and Sample Size Calculations Version 3.0, 2009.

\section{Results}

\section{Pedigree}

Figure 1 shows the pedigree (2 generations) of the family that we studied. The age of PD onset for the affected individuals 3 and 4 in the kindred is 45 and 40, respectively. We failed to discover any mutations of the 9 genetic variants, including rare mutations $\mathrm{E} 46 \mathrm{~K}$ and A1442P originally found in the kindred. It may be caused by low family members to detect the association. Further studies using a larger Chinese pedigree with PD patients are required to determine this.

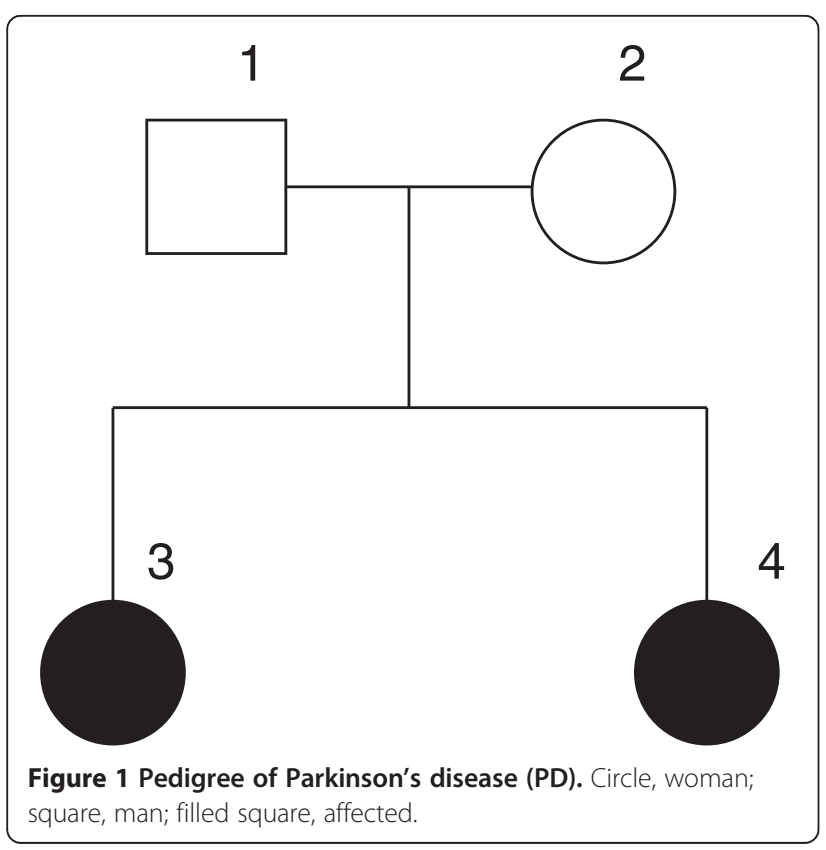

\section{Case-control study}

We analyzed 9 variants, E46K, G2385R, A1442P, IVS9, A350V, P268S, R702W, G908R, and 1007fs in 237 sporadic patients with PD and 190 controls using the PCRRFLP and CE. All the genotypic and allelic distributions analyzed in this study were in accordance with the Hardy-Weinberg equilibrium. No heterozygosity or homozygosity of E46K, A1442P, A350V, R702W, G908R, or $1007 \mathrm{fs}$ was found. Heterozygosity of G2385R, IVS9, and P268S were found in the case groups and controls (Figure 2). The genotype frequency, allele frequency, odds ratios, and confidence interval of these variants are shown in Table 2.

The distribution of G2385R heterozygosity in $L R R K 2$ was significantly different between cases and controls (10.1\% vs. 2.1\%, $P=0.009)$. The intron IVS9 heterozygous variant in PARK2 was found in both the case group (12.7\%) and the control group (7.9\%). Although this variant had a higher frequency in the case group than the control group, the difference was not statistically significant $(P=0.348)$.

Although only 8 out of 237 patients were found to carry the P268S heterozygous variant in NOD2, all these patients ( 2 women and 6 men) had age at onset of over 50 years. Since no controls were found to carry this variant, the difference between cases and controls was slightly significant $(P=0.0450)$. These results suggest that the variant P268S in NOD2 might be associated with late-onset $\mathrm{PD}$ and is one of the risk factors for sporadic PD in Chinese Han populations.

\section{Discussion}

Gene polymorphism is a risk factor of PD, and it shows different distributions in different ethnic groups and geographies. Although GWAS have identified a number of susceptibility genes and relevant variants associated with PD in different populations, few of them have been analyzed in other populations. To best of out knowledge, we first screened 8 variants that have been associated with neurodegeneration, E46K, A1442P, A350V, IVS9, P268S, R702W, G908R, and 1007fs in Chinese populations, and further verified the presence of the highfrequency variant G2385R in southern China.

In case-control study, both PD patients and controls carried the heterozygous G2385R mutation, and the genotype difference was slightly significant. This is consistent with the results of a previous study of 600 Chinese PD patients and 334 controls [30]. This variant was initially reported by Xingkai An. in 2008 among PD patients in Sichuan area [30]. However, we did not find E46K, A1442P, or A350V variants in patients with PD and in controls. All of them indicated following phenomenon: the ancestry effect; familial PD results from rare, highly penetrant pathogenic mutation (e.g. 


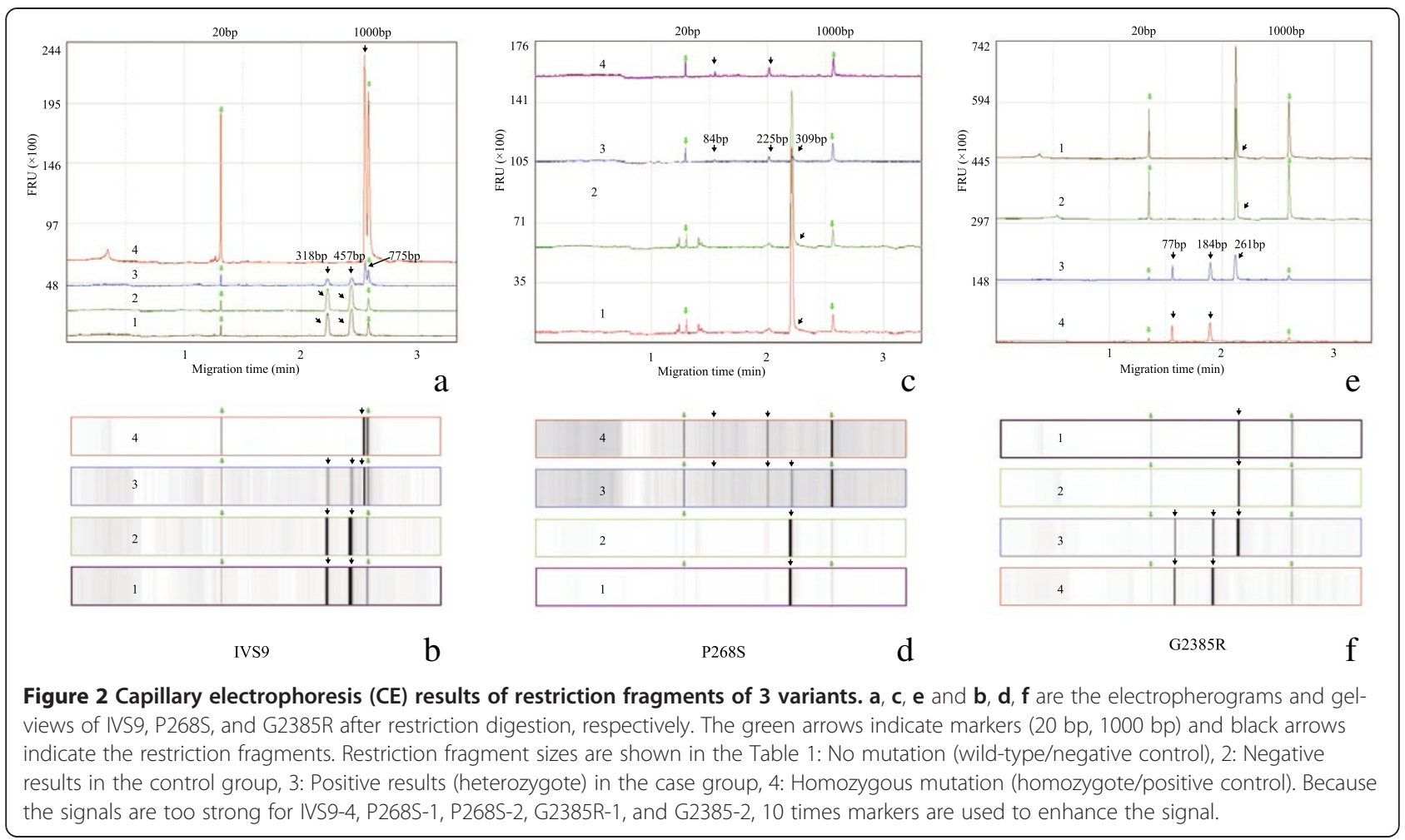

E46K, A1442P); multiple variants of low penetrant (e.g. A350V) contribute to the risk of PD and are involved in the etiology of PD.

Interestingly, none of homozygosity of these variants was found in either the case or control groups [31,32]. It was reported that heterozygosity of autosomal recessive genes was very important in the initiation and development of PD. For example, it has been found that patients with PD who carry heterozygous PARK2 and PINK1 mutations have an age of onset between that of wild-type individuals and patients with homozygous mutations $[33,34]$. Heterozygous mutation carriers indeed show preclinical changes at the metabolic, structural, or functional levels that are detectable by modern techniques of neuroimaging and electrophysiology. Heterozygosity for putative recessive mutations could lead to disease expression by at least three mechanisms which are haploinsuffciency, dominant-negative effect and novel gain-of-function [35]. Taken together, heterozygous mutations in putative recessive genes seem to increase the susceptibility to develop PD.

The new insertion mutation, c.1084intron ${ }^{+}$in PARK2, introduces two new amino acids and a TAA stop codon, resulting in reduced levels of parkin protein [36]. This insertion mutation may be associated with the $-6 \mathrm{G}>\mathrm{A}$ polymorphism of intron 9 in PARK2. One case-control study found IVS9G $>$ A to be a risk factor of PD in Taiwan. A functional study of IVS9G $>$ A by Guey-Jen Lee-Chen showed that the shear efficiency of $-6 \mathrm{~A}$ was slower than that of $-6 \mathrm{G}$ at the protein level [37]. 12.7\% PD patients and $7.9 \%$ controls carried the heterozygous IVS9 mutation, but the allele difference and genotype difference were not statistically significant. This result is consistent with the results of a previous study of 506 patients and 508 controls in Taiwan [18]. Further investigation into the association between IVS9G $>$ A and PD need, through larger sample size from various populations.

Inflammation is one of the suspected theories of PD. The activation of NF- $\mathrm{KB}$ and microglial cells around dopaminergic neurons have been analyzed in patients with PD [38]. In 2007, Monika Bialecka reported that three variants (R702W, G908R, and L1007fsinsC) of NOD2 encoding NOD2, a protein that can activate the apoptosis response, were significantly associated with PD in a Polish population [28]. It has been demonstrated that these three variants are not associated with $C D$ in Chinese Han, Korean, and Japanese populations [39-42]. Similarly, these three common SNPs (R702W, G908R, and 1007fs) were not detected in our cohort. However, a novel variant P268S was observed, which has also been discovered to be associated with $\mathrm{CD}$ in Chinese population [43]. Although linkage disequilibrium was observed between P268S and the other three SNPs in NOD2, only P268S of the four variants was slightly significant in our study, which was consistent with recent study suggesting that P268S instead of 1007fs, G908R, R702W was a risk factor of Chinese Crohn's disease population. It 
Table 2 Genotype and allele frequencies of G2385R, P268S, and IVS9 in cases and controls

\begin{tabular}{|c|c|c|c|c|c|c|c|}
\hline \multirow[t]{2}{*}{ Genotype } & \multicolumn{2}{|c|}{ PD patients, $n=237$} & \multicolumn{2}{|c|}{ Control, $n=190$} & \multirow{2}{*}{$\begin{array}{l}\text { Odds ratio } \\
(95 \% \mathrm{Cl})^{*}\end{array}$} & \multirow[t]{2}{*}{ p value** } & \multirow[t]{2}{*}{ Power $^{\S}$} \\
\hline & No. & $\%$ & No. & $\%$ & & & \\
\hline \multicolumn{8}{|c|}{$\mathrm{G} 2385 R(G>A)$} \\
\hline GG & 213 & 89.9 & 186 & 97.9 & 1 & & \\
\hline \multirow[t]{2}{*}{ GA } & 24 & 10.1 & 4 & 2.1 & 5.24 & 0.009 & 0.8973 \\
\hline & & & & & $(1.79-15.38)$ & & \\
\hline AA & 0 & 0 & 0 & 0 & - & - & \\
\hline G & 450 & 94.9 & 376 & 98.9 & 1 & & \\
\hline \multirow[t]{2}{*}{ A } & 24 & 5.1 & 4 & 1.1 & 5.01 & 0.090 & 0.8803 \\
\hline & & & & & $(1.72-14.58)$ & & \\
\hline \multicolumn{8}{|l|}{$\mathrm{P} 268 \mathrm{~S}(\mathrm{C}>\mathrm{T})$} \\
\hline $\mathrm{CC}$ & 229 & 96.6 & 190 & 100 & 1 & & \\
\hline $\mathrm{CT}$ & 8 & 3.4 & 0 & 0 & - & 0.045 & NA \\
\hline$\pi$ & 0 & 0 & 0 & 0 & - & - & \\
\hline$C$ & 466 & 98.3 & 380 & 100 & 1 & & \\
\hline $\mathrm{T}$ & 8 & 1.7 & 0 & 0 & - & - & \\
\hline \multicolumn{8}{|l|}{$\operatorname{IVS9}(\mathrm{G}>\mathrm{A})$} \\
\hline GG & 207 & 87.3 & 175 & 92.1 & 1 & & \\
\hline \multirow[t]{2}{*}{ GA } & 30 & 12.7 & 15 & 7.9 & 1.7 & 0.348 & 0.2987 \\
\hline & & & & & $(0.88-3.24)$ & & \\
\hline $\mathrm{AA}$ & 0 & 0 & 0 & 0 & - & - & \\
\hline G & 444 & & 365 & 96.1 & 1 & & \\
\hline \multirow[t]{2}{*}{ A } & 30 & 6.3 & 15 & 3.9 & 1.64 & 0.572 & 0.2865 \\
\hline & & & & & $(0.87-3.10)$ & & \\
\hline
\end{tabular}

*: Odds ratios (OR) and $95 \%$ confidence intervals $(95 \% \mathrm{Cl}$ ) were calculated by comparison to the common allele frequencies and genotype frequencies.

**: Fisher exact test and false discovery rate were used to calculate and correct the $p$ values, respectively. Two sided $P$ value $\leq 0.05$ was considered statistically significant.

s: Power was calculated by Power and Sample Size Calculations Version 3.0, 2009. NA: not available.

indicated that P268S may be one of risk factors for PD in Chinese individuals, or the P268S variant may be in linkage disequilibrium with another causal rare variant on NOD2 gene. The frequencies of minor allele 1007fs, G908R, R702W and P268S variants are much lower in Asians compare to Caucasians populations. In this study, genotype frequency of P268S $(P=0.0450)$ had slightly significant differences. The sample size has to be very large or odds ratio has to be very high to have enough power for detection effect of very rare variants.

NOD2 is a member of the Apaf-1 superfamily of apoptosis regulators that is expressed in monocytes and involved in the activation of NF-kB, by bacterial component muramyl dipeptide (MDP) [44]. Functional studies revealed that both normal and P268S NOD2 induced similar levels of NF- $\kappa B$ activation in response to MDP [45] and the G908R, R702W, and L1007fsinsC variants in the presence and absence of P268S are defective in their ability to respond to bacterial lipopolysaccharides and peptidoglycan, whereas P268S alone exhibited wildtype activity [46]. Thus, P268S was confirmed as the haplotype background of these three variants but has no influence on functions of the $\mathrm{CD}$-associated variants of NOD2 [47]. Notably, above results from NF-kB activation assay using human embryonic kidney (HEK) 293 cell lines, but the function activity of NOD2 in neurodegeneration field remain unclear. Additionally, Crane et al. found that carriage of the P268S variant was associated with greater disease activity and inversely associated with ulcerative colitis spondylarthritis [48]. We regarded the P268S of NOD2 behaving as a common factor of PD and CD. Crohn's disease is a chronic inflammatory disorder of the gastrointestinal tract, which is thought to result from the effect of environmental factors in a genetically predisposed host [49]. A wealth of new information has emerged to suggest that inflammation-derived oxidative stress and cytokine dependent toxicity may contribute to nigrostriatal pathway degeneration and hasten progression of disease in humans with idiopathic PD. Both them suggest that inflammation may play a role connecting between PD and $C D$. 


\section{Conclusions}

We analyzed the genetic loci associated with PD in the sporadic and family PD patients using PCR-RFLP and found P268S might be a risk factor of sporadic PD in the Chinese population. As it is the first study on NOD2 P268S in PD patients, the results should be treated with caution, as one cannot completely exclude that they are false positive. Further studies required to verify the association between P268S and susceptibility to sporadic Parkinson's disease in large sample size, and explore the NOD2 functions involved in neurodegenerative diseases.

\begin{abstract}
Abbreviations
PD: Parkinson's disease; SNPS: Single nucleotide polymorphisms; UPS: Ubiquitin proteasome system; PCR: Polymerase chain reaction; RFLP: Restriction fragment length polymorphism; CE: Capillary electrophoresis; GWAS: Genome-wide association studies; CD: Crohn's disease; NOD: Nucleotide-binding and oligomerization domain; EOPD: Earlyonset PD; LOPD: Late-onset PD; UPDRS: Unified parkinson's disease rating scale; EDTA: Ethylene diamine tetraacetic acid; SPSS: Statistical package for the social sciences; OR: Odds ratios; Cl: Confidence intervals; MDP: Muramyl dipeptide; NFAT: Nuclear factor of activated T-cells.
\end{abstract}

\section{Competing interests}

The authors declare that they have no competing interests.

\section{Authors' contributions}

QLM, XKA, and QL collected the blood samples from PD patients and controls, extracted genomic DNA, and searched relevant literature. ZML performed PCR, RFLP, and CE analysis and built positive and negative control plasmids. HJZ and LLC designed the primers for PCR, cloning, and sitedirected mutagenesis and performed sequence alignment. $\mathrm{WQH}$ and $\mathrm{PH}$ participated in statistical analysis and the production of tables. CMT designed all the experiments and drafted the manuscript. All authors read and approved the final manuscript.

\begin{abstract}
Authors' information
QLM: MD, chief physician of the Department of Neurology of the First Affiliated Hospital of Xiamen University; senior visiting scholar at Harvard Medical School, Center of Neurological Diseases; Member of the World Stroke Organization (WSO). XKA: Resident of the Department of Neurology of Xiamen First Hospital; part of the team that first revealed the association of G2385R and the LRRK2 gene with PD in Chinese Han populations. QL: MD, associate-chief physician of the Department of Neurology of the he First Affiliated Hospital of Xiamen University. ZML: Master student, School of Pharmaceutical Sciences Xiamen University; participated in several projects on screening the disease genes for PD of Chinese Han population. CMT: PhD in Physical Biochemistry, Nuclear Science, National Tsing-Hua University, Postdoctoral Fellow in Biochemistry, Stanford University School of Medicine, School of Pharmaceutical Sciences; Executive Director Professor of Center for Translational Medicine, Xiamen University.
\end{abstract}

\section{Acknowledgements}

We would like to thank all the patients and control subjects who participated in this study. We would like to thank Professor Chi-Meng Tzeng for his guidance and the members of our laboratory, Huiming Ye, Xiaonan LV, Yi Li, and Mingjie Lei for their help. This study was supported by Fujian Province Natural Science Foundation Association of glucocerebrosidase gene mutations with Parkinson's disease in Chinese Han patients (No. 2009D001), Fujian Province Health Department Youth Research Projects Association of glutamate transporter gene and patients with Parkinson's disease (No. 2009-2 -72) and Fujian Province Science and Technology Department Key Project of The Screening of Susceptibility Gene in Parkinson's Disease and The Platform Establishment of Molecular Diagnosis (No. 2012D062).

Received: 14 November 2012 Accepted: 1 May 2013

Published: 7 May 2013

\section{References}

1. Zhang ZX, Roman GC, Hong Z, Wu CB, Qu QM, Huang JB, Zhou B, Geng ZP, Wu JX, Wen HB, et al: Parkinson's disease in China: prevalence in Beijing, Xian, and Shanghai. Lancet 2005, 365(9459):595-597.

2. Fahn S: Description of Parkinson's disease as a clinical syndrome. Ann N Y Acad Sci 2003, 991:1-14.

3. Forno LS: Neuropathology of Parkinson's disease. J Neuropathol Exp Neurol 1996, 55(3):259-272.

4. Dauer W, Przedborski S: Parkinson's disease: mechanisms and models. Neuron 2003, 39(6):889-909.

5. Dawson TM, Dawson VL: Molecular pathways of neurodegeneration in Parkinson's disease. Science 2003, 302(5646):819-822.

6. Cookson MR: The biochemistry of Parkinson's disease. Annu Rev Biochem 2005, 74:29-52.

7. Polymeropoulos MH, Lavedan C, Leroy E, Ide SE, Dehejia A, Dutra A, Pike B, Root $\mathrm{H}$, Rubenstein J, Boyer R, et al: Mutation in the alpha-synuclein gene identified in families with Parkinson's disease. Science 1997, 276(5321):2045-2047.

8. Zarranz JJ, Alegre J, Gomez-Esteban JC, Lezcano E, Ros R, Ampuero I, Vidal L, Hoenicka J, Rodriguez O, Atares B, et al: The new mutation, E46K, of alphasynuclein causes Parkinson and Lewy body dementia. Ann Neurol 2004, 55(2):164-173.

9. Kruger R, Kuhn W, Muller T, Woitalla D, Graeber M, Kosel S, Przuntek H, Epplen JT, Schols L, Riess O: Ala30Pro mutation in the gene encoding alpha-synuclein in Parkinson's disease. Nat Genet 1998, 18(2):106-108.

10. Chan DK, Mellick G, Cai H, Wang XL, Ng PW, Pang CP, Woo J, Kay R: The alpha-synuclein gene and Parkinson disease in a Chinese population. Arch Neurol 2000, 57(4):501-503.

11. Mata IF, Wedemeyer WJ, Farrer MJ, Taylor JP, Gallo KA: LRRK2 in Parkinson's disease: protein domains and functional insights. Trends Neurosci 2006, 29(5):286-293.

12. Tan EK, Shen H, Tan LC, Farrer M, Yew K, Chua E, Jamora RD, Puvan K, Puong KY, Zhao Y, et al: The G2019S LRRK2 mutation is uncommon in an Asian cohort of Parkinson's disease patients. Neurosci Lett 2005, 384(3):327-329.

13. Funayama M, Li Y, Tomiyama $H$, Yoshino $H$, Imamichi $Y$, Yamamoto $M$, Murata M, Toda T, Mizuno Y, Hattori N: Leucine-rich repeat kinase 2 G2385R variant is a risk factor for Parkinson disease in Asian population. Neuroreport 2007, 18(3):273-275.

14. Huang Y, Halliday GM, Vandebona H, Mellick GD, Mastaglia F, Stevens J, Kwok J, Garlepp M, Silburn PA, Horne MK, et al: Prevalence and clinical features of common LRRK2 mutations in Australians with Parkinson's disease. Mov Disord 2007, 22(7):982-989.

15. Lucking CB, Durr A, Bonifati V, Vaughan J, Michele G, Gasser T, Harhangi BS, Meco G, Denefle P, Wood NW, et al: Association between early-onset Parkinson's disease and mutations in the parkin gene. N Engl J Med 2000, 342(21):1560-1567.

16. Shimura H, Hattori N, Kubo S, Mizuno Y, Asakawa S, Minoshima S, Shimizu $\mathrm{N}$, Iwai K, Chiba T, Tanaka K, et al: Familial Parkinson disease gene product, parkin, is a ubiquitin-protein ligase. Nat Genet 2000, 25(3):302-305.

17. Mata IF, Lockhart PJ, Farrer MJ: Parkin genetics: one model for Parkinson's disease. Hum Mol Genet 2004, 13:R127-R133. Spec No 1.

18. Wu YR, Wu CH, Chao CY, Kuan CC, Zhang WL, Wang CK, Chang CY, Chang YC, Lee-Chen GJ, Chen CM: Genetic analysis of Parkin in early onset Parkinson's disease (PD): Novel intron $9 \mathrm{~g}>$ a single nucleotide polymorphism and risk of Taiwanese PD. Am J Med Genet B Neuropsychiatr Genet 2010, 153B(1):229-234.

19. Tucci A, Nalls MA, Houlden H, Revesz T, Singleton AB, Wood NW, Hardy J, Paisan-Ruiz C: Genetic variability at the PARK16 locus. Eur J Hum Genet 2010, 18(12):1356-1359.

20. Kolisek M, Launay P, Beck A, Sponder G, Serafini N, Brenkus M, Froschauer EM, Martens H, Fleig A, Schweigel M: SLC41A1 is a novel mammalian Mg2 + carrier. J Biol Chem 2008, 283(23):16235-16247.

21. Wyss-Coray T, Mucke L: Inflammation in neurodegenerative disease-a double-edged sword. Neuron 2002, 35(3):419-432.

22. McGeer PL, McGeer EG: Inflammation and neurodegeneration in Parkinson's disease. Parkinsonism Relat Disord 2004, 10(Suppl 1):S3-S7.

23. Kim YS, Joh TH: Microglia, major player in the brain inflammation: their roles in the pathogenesis of Parkinson's disease. Exp Mol Med 2006, 38(4):333-347. 
24. Hakansson A, Westberg L, Nilsson S, Buervenich S, Carmine A, Holmberg B, Sydow $O$, Olson L, Johnels B, Eriksson E, et al: Interaction of polymorphisms in the genes encoding interleukin-6 and estrogen receptor beta on the susceptibility to Parkinson's disease. Am J Med Genet B Neuropsychiatr Genet 2005, 133B(1):88-92.

25. Kaltschmidt B, Heinrich M, Kaltschmidt C: Stimulus-dependent activation of NF-kappaB specifies apoptosis or neuroprotection in cerebellar granule cells. Neuromolecular Med 2002, 2(3):299-309.

26. Hirsch EC, Hunot S: Neuroinflammation in Parkinson's disease: a target for neuroprotection? Lancet Neurol 2009, 8(4):382-397.

27. Inohara N, Nunez G: NODs: intracellular proteins involved in inflammation and apoptosis. Nat Rev Immunol 2003, 3(5):371-382.

28. Bialecka M, Kurzawski M, Klodowska-Duda G, Opala G, Juzwiak S, Kurzawski G, Tan EK, Drozdzik M: CARD15 variants in patients with sporadic Parkinson's disease. Neurosci Res 2007, 57(3):473-476.

29. Hughes AJ, Daniel SE, Kilford L, Lees AJ: Accuracy of clinical diagnosis of idiopathic Parkinson's disease: a clinico-pathological study of 100 cases. J Neurol Neurosurg Psychiatry 1992, 55(3):181-184.

30. An XK, Peng R, Li T, Burgunder JM, Wu Y, Chen WJ, Zhang JH, Wang YC, Xu YM, Gou YR, et al: LRRK2 Gly2385Arg variant is a risk factor of Parkinson's disease among Han-Chinese from mainland China. Eur J Neurol 2008, 15(3):301-305.

31. Abou-Sleiman PM, Muqit MM, McDonald NQ, Yang YX, Gandhi S, Healy DG, Harvey K, Harvey RJ, Deas E, Bhatia K, et al: A heterozygous effect for PINK1 mutations in Parkinson's disease? Ann Neurol 2006, 60(4):414-419.

32. Klein C: Implications of genetics on the diagnosis and care of patients with Parkinson disease. Arch Neurol 2006, 63(3):328-334.

33. Hedrich K, Marder K, Harris J, Kann M, Lynch T, Meija-Santana H, Pramstaller PP, Schwinger E, Bressman SB, Fahn S, et al: Evaluation of 50 probands with early-onset Parkinson's disease for Parkin mutations. Neurology 2002, 58(8):1239-1246

34. Sun M, Latourelle JC, Wooten GF, Lew MF, Klein C, Shill HA, Golbe LI, Mark $\mathrm{MH}$, Racette BA, Perlmutter JS, et al: Influence of heterozygosity for parkin mutation on onset age in familial Parkinson disease: the GenePD study. Arch Neurol 2006, 63(6):826-832.

35. Klein C, Lohmann-Hedrich K, Rogaeva E, Schlossmacher MG, Lang AE: Deciphering the role of heterozygous mutations in genes associated with parkinsonism. Lancet Neurol 2007, 6(7):652-662.

36. Matsuda N, Kitami T, Suzuki T, Mizuno Y, Hattori N, Tanaka K: Diverse effects of pathogenic mutations of Parkin that catalyze multiple monoubiquitylation in vitro. J Biol Chem 2006, 281(6):3204-3209.

37. Wan-Ling Zhang C-HW, Tsu-Wei W, Lee-Chen G-J: Functional Analysis of Parkin Gene Intron $9 \mathrm{~g}>$ a SNP. Bio Formosa 2010, 45(1):31-38.

38. Hunot S, Brugg B, Ricard D, Michel PP, Muriel MP, Ruberg M, Faucheux BA, Agid $Y$, Hirsch EC: Nuclear translocation of NF-kappaB is increased in dopaminergic neurons of patients with parkinson disease. Proc Natl Acad Sci USA 1997, 94(14):7531-7536.

39. Gao M, Cao Q, Luo LH, Wu ML, Hu WL, Hu WL, Si JM: [NOD2/CARD15 gene polymorphisms and susceptibility to Crohn's disease in Chinese Han population]. Zhonghua Nei Ke Za Zhi 2005, 44(3):210-212

40. Croucher PJ, Mascheretti S, Hampe J, Huse K, Frenzel H, Stoll M, Lu T, Nikolaus S, Yang SK, Krawczak M, et al: Haplotype structure and association to Crohn's disease of CARD15 mutations in two ethnically divergent populations. Eur J Hum Genet 2003, 11(1):6-16.

41. Yamazaki K, Takazoe M, Tanaka T, Kazumori T, Nakamura Y: Absence of mutation in the NOD2/CARD15 gene among 483 Japanese patients with Crohn's disease. J Hum Genet 2002, 47(9):469-472.

42. Leong RW, Armuzzi A, Ahmad T, Wong ML, Tse P, Jewell DP, Sung JJ: NOD2/CARD15 gene polymorphisms and Crohn's disease in the Chinese population. Aliment Pharmacol Ther 2003, 17(12):1465-1470.

43. Lv C, Yang X, Zhang Y, Zhao X, Chen Z, Long J, Zhong C, Zhi J, Yao G, Jiang $B$, et al: Confirmation of three inflammatory bowel disease susceptibility loci in a Chinese cohort. Int J Colorectal Dis 2012, 27(11):1465-1472.

44. Ogura Y, Inohara N, Benito A, Chen FF, Yamaoka S, Nunez G: Nod2, a Nod1/Apaf-1 family member that is restricted to monocytes and activates NF-kappaB. J Biol Chem 2001, 276(7):4812-4818.

45. Inohara N, Ogura Y, Fontalba A, Gutierrez O, Pons F, Crespo J, Fukase K, Inamura S, Kusumoto S, Hashimoto $M$, et al: Host recognition of bacterial muramyl dipeptide mediated through NOD2. Implications for Crohn's disease. J Biol Chem 2003, 278(8):5509-5512.
46. Bonen DK, Ogura Y, Nicolae DL, Inohara N, Saab L, Tanabe T, Chen FF, Foster SJ, Duerr RH, Brant SR, et al: Crohn's disease-associated NOD2 variants share a signaling defect in response to lipopolysaccharide and peptidoglycan. Gastroenterology 2003, 124(1):140-146.

47. Chamaillard M, Philpott D, Girardin SE, Zouali H, Lesage S, Chareyre F, Bui TH, Giovannini M, Zaehringer U, Penard-Lacronique V, et al: Geneenvironment interaction modulated by allelic heterogeneity in inflammatory diseases. Proc Natl Acad Sci USA 2003, 100(6):3455-3460.

48. Crane AM, Bradbury L, Van Heel DA, McGovern DP, Brophy S, Rubin L, Siminovitch KA, Wordsworth BP, Calin A, Brown MA: Role of NOD2 variants in spondylarthritis. Arthritis Rheum 2002, 46(6):1629-1633.

49. Ogura Y, Bonen DK, Inohara N, Nicolae DL, Chen FF, Ramos R, Britton H, Moran T, Karaliuskas R, Duerr RH, et al: A frameshift mutation in NOD2 associated with susceptibility to Crohn's disease. Nature 2001, 411(6837):603-606.

doi:10.1186/1744-9081-9-19

Cite this article as: Ma et al:: P268S in NOD2 associates with susceptibility to Parkinson's disease in Chinese population. Behavioral and Brain Functions 2013 9:19.

\section{Submit your next manuscript to BioMed Central and take full advantage of:}

- Convenient online submission

- Thorough peer review

- No space constraints or color figure charges

- Immediate publication on acceptance

- Inclusion in PubMed, CAS, Scopus and Google Scholar

- Research which is freely available for redistribution

Submit your manuscript at www.biomedcentral.com/submit
C Biomed Central 